\title{
TRANSFORMATIONAL DIMENSIONS OF SCIENCE UNDER GLOBALIZATION CHALLENGES
}

\author{
Oleh Hubanov' ${ }^{1}$, Serhii Mosondz², Oleh Melnychuk ${ }^{3}$
}

\begin{abstract}
The precise and correct understanding of the transformational changes in the field of science, which are constantly kept under public review, is vitally important for civilizational development of the Ukrainian State. Problem statement. Although some specific and significant aspects of science are highlighted and respective innovations are suggested, very often there is a lack of methodological reasoning and non-systemic of recommendations. The abovementioned stipulates the need to formulate a complete and perfect vision of the science transformation at the present stage of the Ukrainian society's development. The purpose of this paper is to formulate the author's conception of the necessity of science transformation in Ukraine by analysing global challenges and critical study of modern scientists' works. The achievement of the formulated aim is carried out by the means of the complex and consistent application of the corresponding scientific tool presented by such methods of scientific knowledge as: logical-semantic, systematic, structural-logical, methods of grouping, deduction, induction, analysis and synthesis etc. Results. In the article, the author establishes and explains the reasons for the transformational changes in the field of science, which are reduced to the following: global character of human development; an advanced approach to the interaction of theory and practice in the context of the implementation of scientific activities; development of modern information technologies; insufficient support by the state and society of science and scholars; absence of an integrated approach, focused on the fundamental integrity and complexity of the system "science - education production"; aggravation of social and economic problems; integration of the innovative type of civilization. To sum up, the author concludes that civilizational society has dramatically influenced the development of science, significantly accelerating the processes of its development. Modern science, as well as scientists' activity, is impossible without the use of the latest technologies. This activity, in turn, promotes the development of newer technologies. The speed of these processes is constantly increasing and the transformation of science in one sphere instantly causes transformation in another. Such changes lead to the emergence of an incredibly large number of scientific knowledge that needs to be perceived and embodied in practice.
\end{abstract}

Key words: science, transformation, globalization, conceptual approaches, foundations, civilization, development, efficiency, intensity.

JEL Classification: A11, E00, 125

\section{Introduction}

To date, Ukraine is at the beginning of the great path to civilized integration into the global and European scientific area. Our state will remain the country, which provides the intellectual potential for scientifically advanced countries until it acquires the recognized status of a subject enjoying equal rights in the sphere of foreign scientific cooperation.

Further success of economic transformations, continuous economic growth will depend on the reform of the national scientific system, which should be based on the principles of innovation through

\footnotetext{
Corresponding author:

${ }^{1}$ Taras Shevchenko National University of Kyiv, Ukraine.

E-mail: gubanof@ukr.net

${ }^{2}$ Education and Research University of Modern Knowledge, Ukraine.

E-mail: 40533@ukr.net

${ }^{3}$ Education and Research University of Modern Knowledge, Ukraine.

E-mail: melnychuk_op@gmail.com
}

the use of modern information and communication technologies.

Research works by famous researchers, such as Yu. Anisimov, B. Arutiunov, A. Berdashevich, D. Bernal, V. Vernadskyi, F. Brokgauz, P. Haidenko, V. Danylevskyi, H. Dobrov, Ye. Zolotukhin, I. Yefron, O. Krasovska, J. Condorcet, V. Kokhanovskyi, L. Kosarieva, Th. Kuhn, B. Kuznietsov, O. Lietov, B. Malitskyi, L. Markova, O. Popovych, K. Popper, M. Rozov, B. Starostin, V. Stopin, and others, contain different substantiations and conditions for reorientation of science. 
Nowadays the issue of transformation of changes in the field of science is constantly in the power of public opinion. Some important aspects of science are highlighted, relevant innovations are offered, but methodological weakness, unsystematic suggestions are often perceived.

Therefore, the purpose of this paper is to highlight the general vision of the transformation of science under the intensification of globalization processes.

\section{Grounds for the need for transformational changes in the field of science for the Ukrainian state}

The transformation of science at the present stage of the development both of the world community and Ukrainian society is justified and obvious. Herewith the logical question dealing with the need for transformational changes in the field of science for the Ukrainian state arises. Let's try to answer it by defining the grounds for these changes.

Firstly, the development of mankind has become global, which makes competitive only the person and the state capable of living and acting in such a space.

The issue of globalization relates to global conflict because it raises the most important question of mankind dealing with the prospect of the world system. It is difficult to form effective mechanisms for the interaction of societies in the global civilization progress without an equal dialogue of cultures, without taking into account the scientific potential and prospects for the development of each civilization.

Therefore, it is no coincidence that the main emphases relating to the comprehension of the possible globalization consequences are put on the need to refer to science, culture, where spirituality as an expression of moral principles of social life and moral rules of human behaviour in society prevails.

It is obvious that the scientific potential of the nation in the 21 st century will be almost the main productive force while choosing geo-economic and geo-political models of the future and forming a new paradigm of civilization development. Consequently, preservation of the national essence, national identity, cultural and scientific uniqueness is an essential part of the state policy as a whole and the policy of the scientific and humanitarian development of society in particular.

Secondly, modern civilization has substantially expanded the approach to the interaction of theory and practice in the context of performing research activity. That is, today the relationship between knowledge and practice is not limited to the division into fundamental and applied one when fundamental knowledge is understood as theoretical one but applied knowledge as the one that can be used in practice of production or as the one that can arise from it. Modern knowledge results from more complex relationships between such research ideas that can be determined as theoretical and practical ones. It's about researching as practising, getting fundamental knowledge while practising. For instance, in the field of modern biotechnology research, the concept of practice is used quite organically and innovative biotechnological practices are being studied as emerging in the field of fundamental research (Nikolaienko, 2009).

Therefore, modern science shall take into account situations where diverse and rather complicated research practices begin to precede theories. As sociologist L. Bevzenko notes, the theory as a scientific, philosophical, and practical reality becomes only a practical guide to certain, rather narrow spheres of human life. In this case, more powerful semantic type of constellation helps to perceive different kinds of practices as its individual manifestations, and scientific, philosophical, and practical ones turn out to be only similar to a number of other similar manifestations (Bevzenko, 2008). Knowledge as practising foresees the moment of design, projection, and technological capability.

Thirdly, the modern world has set the science other tasks and has created new opportunities for it. First and foremost, these are up-to-date information technologies, nanotechnologies, robotics, which provide at least two functions, namely computer literacy, as well as individualization and intensification of the research process.

While stating this ground, it is necessary to focus on the fact that at the present stage of the development of the world community, a person exists in a world where human factors are almost absorbed by technological ones. Thus, the issue of human freedom arises as one of the principal metaphysical issues of the 21st century. The book "Polysubstantial Homo: Philosophic and Artistic Thought in Search of non-Euclidean Reflectivity" by V. Tabachkovskyi emphasizes that, unlike modernity based on the unlimited concept of freedom, first of all, postmodernity is based on the idea of freedom as a personal choice, the decision is related to the subjective world of personalities existing between the universality of human nature and the peculiarity of individuality (Tabachkovskyi, 2005). It previously seemed that the most favourable situation for a person was widening of the possibilities of simultaneous choice but nowadays it became clear that the connection of such a choice with the perception of personal identity is more important. Therefore, it is better for mankind and strictly for a personality, so that such an identity could be found also in a special, individually unique area, and not just in an identical one.

Fourthly, insufficient support of science and scholars by the state and society, which does not allow carrying out ripe transformations opportunely and to a due extent. Fundamental and applied researches were separated from real economic needs, and the research system in general and individual research groups in particular lost the ability to 
objective self-assessment. This resulted in a decrease in the competitive level of products and undoubtedly influenced the level of competitiveness of Ukrainian output.

Fifthly, experience confirms that issues of scientific advancement, implementation of inventions, organization and stimulation of technical progress in enterprises, training of research personnel cannot be isolated from each other. One cannot expect a significant success by solving each of them separately.

An integrated approach focused on the fundamental integrity and complexity of the system "science - education - production" is essential here. A narrow, simplified approach to implementation of inventions is incompatible with the current scale and pace of scientific and technological progress.

The scientific and industrial cycle is a national economic cycle of new knowledge covering fundamental research, applied products and material output. The emergence of the scientific and production cycle reflects the integration processes that have arisen in the field of science and production in the first quarter of the 20th century and intensified after the Second World War. Now they are crucial for implementing an innovation development model.

Nowadays both in Ukraine and in other post-Soviet Republics, one can observe violation of the conditions for the organization and functioning of the cyclical paradigm: "science - education - production" and its centric stages (fundamental research, scientific and applied products, research and design work, projection, technological preparation for manufacture, implementation of innovations, extensive prevalence of innovations to full market saturation). This, in particular, discourages foreign investors from investing capital in our economy.

Due to partial closing of research institutes, a significant deterioration of the conditions for sectoral and intersectoral applied products also provokes concerns. This problem is mostly related to the incomprehension of the fact that science can be efficient only when it organically joins the sphere of the research and production cycle thorough educated experts.

Sixthly, aggravation of socio-economic problems caused by objective difficulties of the transition period, as well as by serious errors in the definition of the model of transformation processes, gradually eliminated science from a number of state priorities, which resulted both in multiple reductions in investment in scientific and technological development and in loss of innovation activity of the economy.

And, seventhly, nowadays Ukraine has entered the new type of civilization, namely innovation one. Its feature is constant changeability, the dynamism of change. Changes in knowledge, technology, information, circumstances of life etc. occur, and these changes are much faster than the change of generation of people. The knowledge gained becomes outdated, a need for new knowledge arises.
In our opinion, the last factor in the transformation of science is fundamental and requires detailed concretization in light of globalization processes taking place in the world community.

\section{Efficient use of science-based potential, its restructuring and the formation of a national innovation system}

The nature of economic growth, the competitiveness of the country in the world market, its national security are determined not by the volume of physical resources, but they depend on how society can create and effectively use the scientific factor, develop innovative activities and innovation processes at all levels of government. In modern Ukraine, the solution of key socio-economic problems is also impossible without efficient use of science-based potential, its restructuring, and the formation of a national innovation system. The practice of reforming the national economy has shown that the market is not able to solve all the problems of overcoming the degradation of the technological base of production and the formation of new technological regimes to the extent necessary to ensure sustainable economic growth in our country and its regions. The problem determines the need to strengthen the role of the state in the scientific support of innovation processes and in the regulation of the innovation sphere in general. The importance of the early formation of an effective state policy in the field of science and, in particular, its component such as an innovative policy is growing.

Today the need for innovative development of Ukraine is the need to keep pace with time in accordance with current realities, to be up to standards of the developed countries of the world. A political prerequisite for the innovative development of Ukraine is the need to win a worthy place in the international community of civilized peoples. The latter respect the states that offer innovative ideas and models of development, show examples of success in one or another sphere of public life. Therefore, an accelerated entry into the civilization process on the basis of innovative strategies is one of the basic political tasks of Ukrainian state building and strengthening of Ukraine's competitiveness in Europe and in the world.

Science is considered as the most important source, rather, as the sphere of birth of innovations, because this area of activity concentrates the main resources and the most favourable conditions for a special intellectual work, which generates innovations.

In the scientific sphere, knowledge is mostly transformed into basic, systemic innovations that have the greatest updating capabilities. But these innovations, as a rule, are always capital-intensive and do not always have the opportunity of commercialization. Therefore, their creation requires powerful state support.

In turn, innovation technology offers the scientific community the radical innovations that, being a part of 
the research, lead to profound changes - and not only positive - in the organization of research activity and to the transformation of science in general.

At the present stage of the development of the international community, the system of scientific knowledge is international, which, at first sight, makes science more prone to international integration. However, in fact, here there are problems relating to the fact that science is not only a cognitive institution, but it is also a social one. The most serious difficulties arise at the junction of new technological opportunities and old political purposes. Innovations have created a global opportunity for genuine scientific cooperation limited neither by distances nor by state borders and easily carried out in real time. But in reality, if one does not consider science as a system of knowledge, but as a sphere of activity, global science does not exist because it is organized under the national principle and in the national framework, it is also divided by departmental barriers. Of course, science must be open, that is, scientific knowledge must be accessible to all. But the one who spends his/her money on it naturally wants to have some benefits. The democratic idea of open science, that is, the international use of fundamental scientific knowledge, encounters the reality of the national costs of obtaining new knowledge and its keeping. International scientific projects must overcome the differences, sometimes very substantial, of the national interests of their participants. However, since these antinomies exist in light of the apparent tendency of the globalization of the world economy, it is obvious that the transformation of science in the same direction is also inevitable in the future.

\section{Conclusions}

Civilization society has fundamentally influenced the development of science, greatly accelerating the processes of its development. It is impossible to imagine modern science and activity of researches without the use of innovative technologies. This activity favours the development of newer technologies. The speed of these processes is constantly increasing and the transformation of science in one sphere instantly causes the transformation in another one. Such changes result in the emergence of an incredibly large number of scientific knowledge that needs to be perceived and put into practice.

\section{References:}

Nikolaienko, N. V. (2009). Biotekhnolohichni praktyky v konteksti synerhetychnoi metodolohii [Biotechnological practices in the context of synergetic methodology]. Praktychna filosofiia, 4(34), 10-15.

Bevzenko, L. D. (2008). Postneklassichekie praktiki vlogike gabitualnykh transformatsiy [Postnonclassical practices in the logic of habitual transformations]. Proceedings of the Postneklassichekie praktiki: opredelenie prdmetnykh oblastey: Materialy mezhdunarodnogo mezhdistsiplinarnogo seminara (eds. Astaf'eva O. N.), Moscow: MAKS Press.

Tabachkovskyi, V. H. (2005). Polisutnisne homo: filosofsko-mystetska dumka v poshukakh «neevklidovoi reflektyvnosti» [Poliessental homo: philosophical and artistic thought in the search for «non-Euclidean reflectivity $\gg$. Kyiv: PARAPAN. 